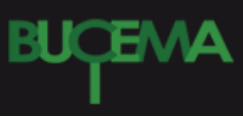

Bulletin du centre d'études médiévales d'Auxerre | BUCEMA

Hors-série $n^{\circ} 4 \mid 2011$

Autour de l'autel chrétien médiéval

\title{
Le Christ-roi : Autel et couronne votive dans l'Espagne wisigothique
}

\section{Thomas Deswarte}

\section{(2) OpenEdition \\ 12 Journals}

\section{Édition électronique}

URL : https://journals.openedition.org/cem/11757

DOI : 10.4000/cem. 11757

ISSN : 1954-3093

Éditeur

Centre d'études médiévales Saint-Germain d'Auxerre

Référence électronique

Thomas Deswarte, «Le Christ-roi : Autel et couronne votive dans l'Espagne wisigothique », Bulletin du centre d'études médiévales d'Auxerre | BUCEMA [En ligne], Hors-série n 4 | 2011, mis en ligne le 01 juin 2011, consulté le 02 mars 2023. URL : http://journals.openedition.org/cem/11757 ; DOI : https:// doi.org/10.4000/cem. 11757

Ce document a été généré automatiquement le 2 mars 2023.

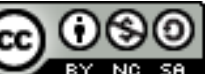

Creative Commons - Attribution - Pas d'Utilisation Commerciale - Partage dans les Mêmes Conditions 4.0 International - CC BY-NC-SA 4.0

https://creativecommons.org/licenses/by-nc-sa/4.0/ 


\title{
Le Christ-roi : Autel et couronne votive dans l'Espagne wisigothique
}

\author{
Thomas Deswarte
}

Depuis la découverte en 1858 d'un trésor à deux kilomètres du village de Las Huertas de Guarrazar (à une dizaine de kilomètres de Tolède), ses objets précieux, en particulier des couronnes et des croix en or ornées de perles et de pierres, ont connu diverses vicissitudes ${ }^{1}$ : tandis qu'une partie de ce trésor disparaissait définitivement en raison de l'intervention trop tardive de l'Etat espagnol, plusieurs pièces parvenaient en France ; en outre, furent volées en 1921 au Palais royal de Madrid trois pièces, notamment la fameuse couronne du roi Suinthila - dont nous avons heureusement conservé quelques photographies. Grâce au retour de cinq couronnes et de trois croix en Espagne - lors d'un échange d'oeuvres d'art conclu en 1941 entre les gouvernements du général Franco et du maréchal Pétain - la plupart des objets sont désormais à Madrid, au Palais royal et au Musée Archéologique National; quelques autres se trouvent encore au Musée de Cluny (Paris).

2 Les pièces conservées, sept croix et dix couronnes votives, donnent une idée de l'incroyable richesse du trésor initial, dont le contexte demeure malheureusement très mal connu en raison des très insuffisantes fouilles de 1859. Néanmoins, de récentes investigations archéologiques nous ont appris qu'il fut enfoui dans deux sépultures occidentales d'une petite nécropole, orientée est-ouest et organisée en trois rangées. Cette nécropole était située à côté d'une chapelle vraisemblablement édifiée au milieu du septième siècle et contenant la sépulture d'un prêtre, Crispin, datée de la fin de ce même siècle ${ }^{2}$. Ces joyaux étaient assurément en partie d'origine royale, puisque deux couronnes furent offertes par les souverains wisigoths, dont les lettres pendantes nous révèlent l'identité : Suinthila (621-631) (+ SU[IN]T[H]IL[A]NUS REX OFFE[RE]T) et Réceswinthe (653-672) (+ RECCESVINTHUS REX OFFERET). Elles étaient suspendues dans une ou plusieurs églises, dont la localisation demeure inconnue, qu'il s'agisse de Guarrazar, des environs ou, plus probablement, de Tolède.

3 Deux autres couronne votives sont indirectement attestées depuis la découverte en 1926, dans une olivaie non loin de Torredonjimeno (Majanos de Garañón, province de 
Jaén), d'un autre trésor composé notamment de plusieurs croix et de lettres pendantes ${ }^{3}$. Or, si, dans un cas, ces dernières nous livrent les saintes bénéficiaires de l'offrande (IUSTE et RUFINE), trois autres lettres pourraient composer le mot REX et avoir ainsi appartenu à une couronne d'origine royale. Ces deux trésors furent vraisemblablement enfouis lors d'une guerre, puisque le septième canon du concile de Tolède XIII (683) autorisait l'évêque à déposer les luminaria de son église en cas de menace militaire ${ }^{4}$; peut-être faut-il y voir une conséquence de l'invasion musulmane de 711 - bien qu'aucune preuve tangible ne vienne étayer cette hypothèse.

4 Cette pratique de suspendre des couronnes, des croix et des lampes à huile dans les églises, entre les colonnes et au-dessus des autels, était fort répandue en Orient, comme le prouve l'iconographie de plusieurs Evangéliaires byzantins et arméniens, mais aussi en Occident, par exemple à Rome selon le Liber Pontificalis ${ }^{5}$. Comment expliquer cette coutume? Javier Arce a rapproché ces couronnes de l'or coronaire, c'est-à-dire de cette taxe extraordinaire payée au Bas-Empire par les curiales, notables chargés de la gestion des cités, à l'occasion de l'avènement, d'un anniversaire ou d'un jubilé de l'empereur. Surtout, à la suite d'oleg Grabar, il donna à cette pratique une signification essentiellement religieuse: ces offrandes seraient de précieux "ornements", témoignant d'un acte de piété et mettant en valeur le sacré du sanctuaire et les vertus $\mathrm{du}$ donateur ${ }^{6}$.

5 Faut-il pour autant minorer la symbolique même de la couronne, et y voir, à la suite de Javier Arce et de María R. Valverde Castro, un simple "ornement» de "forme circulaire »?? Dans le monde byzantin, la couronne votive est pourtant fréquemment associée au pouvoir impérial, à l'instar de ces coronas imperatorum ex auro vel gemmis signalées dans l'Anastasis du Saint-Sépulcre par l'Itinerarium d'Antoine de Plaisance ${ }^{8}$. En fait, la couronne votive était bien dans l'ensemble du monde romano-chrétien un insigne du pouvoir royal (I). En outre, la suspension des couronnes au-dessus des autels acquit dans l'Espagne wisigothique une valeur liturgique, théologique et idéologique, glorifiant les royautés tout à la fois céleste et terrestre (II).

\section{Des couronnes royales}

6 A l'époque wisigothique, la couronne royale est attestée à de multiples reprises dans plusieurs monarchies romano-germaniques ${ }^{9}$. Elle dérivait du diadème romain tardoantique, c'est-à-dire de cette bande de soie et de fils d'or nouée derrière la nuque, qui faisait partie des insignes impériaux depuis son introduction par Constantin sur les monnaies ${ }^{10}$. Ce bandeau, perlé sur les pièces à partir du règne de Constance II (337-361), est attesté par la vita Martini à la fin du quatrième siècle, quand Sulpice Sévère décrit une apparition à Martin du diable travesti en Christ-empereur, « revêtant également le costume du souverain, ceignant un diadème de pierres précieuses et d'or $»^{11}$. Il évolua ensuite vers le diadème de métal précieux orné de pierreries, suivant une chronologie difficile à déterminer. La forme classique de la couronne apparut en Orient sur les monnaies de Tibère II (578-582); mais ce ne fut qu'à partir de 632, avec Héraclius (610-641), que l'empereur et ses fils furent systématiquement couronnés sur les solidi.

7 Logiquement, les termes de corona et de diadema ne désignaient donc pas deux objets fondamentalement différents, mais révélaient une confusion terminologique autour d'un même objet ${ }^{12}$. Certes, la corona était surtout le symbole de la victoire ou du martyre: selon le Liber Judicum, «le bon prince (...) aura le repos éternel après ces 
temps éphémères, le royaume des cieux après le jaune de l'or, la gloire et la couronne après le diadème et le pourpre $»^{13}$. Cependant, tandis que la couronne des saints était occasionnellement nommée diadema ${ }^{14}$, l'insigne du pouvoir souverain fut parfois appelé corona, car "posée sur la tête des rois " selon Isidore de Séville (601-636) : la couronne était "l'insigne de la victoire ou la marque de l'honneur royal», de sorte que "les empereurs romains [i.e. de Constantinople] et certains rois de peuples utilisent des couronnes d'or $»^{15}$.

La brève description par Isidore dans son Historia Gothorum du couronnement de Reccarède (586-601), après la mort de son père Léovigilde (569-586), n'était donc pas une "métaphore" de son arrivée au pouvoir ${ }^{16}$ ou de "la récompense [i.e. céleste], anticipée sans doute, de son zèle pour l'Eglise $\aleph^{17}$. Même s'il n'existait à proprement parler aucune cérémonie de couronnement, la narration historique de l'évêque de Séville supposait bien l'existence d'une couronne royale vers 600. Leovigildo defuncto Recaredus regno est coronatus, cultu praeditus religionis et paternis moribus longe dissimilis ${ }^{18}$ doit donc être traduit : «Après la mort de Léovigilde, Reccarède fut couronné pour la royauté [et non de la royauté], lui qui était respectueux de la religion et très différent de son père ». A l'instar du roi Liutprand des Lombards qui, d'après le Liber Pontificalis, remit en 728 devant l'autel de Saint-Pierre de Rome plusieurs objets parmi lesquels une "couronne d'or ${ }^{19}$, le roi wisigoth offrait sa royauté au Christ en donnant une couronne à une église ${ }^{20}$.

Dans l'Espagne wisigothique, les couronnes votives ressemblent aux autres modèles iconographiques de coronae royales. En témoignent les bustes de profil des tremisses wisigothiques, qui représentent des rois - peut-être Léovigilde, sûrement Réceswinthe - portant une couronne ajourée et des infules ${ }^{21}$; or, si ces représentations dépendent de modèles antérieurs byzantins ${ }^{22}$, elles rappellent aussi les joyaux de Guarrazar. De même, les miniatures du codex de Vigila, réalisé dans la Rioja au monastère San Martín de Albelda en 974/976 à partir de modèles antérieurs ${ }^{23}$, contiennent deux portraits de Réceswinthe lors des conciles de Tolède IX et $\mathrm{X}^{24}$ : il y porte un disque en or enrichi de pierres précieuses, qui n'est pas sans évoquer les deux couronnes royales de Guarrazar.

Cette similitude entre les couronnes votives et les autres couronnes royales est enfin confirmée par le fameux récit de l'usurpation du duc Paul contre Wamba en 673, narré par Julien de Tolède dans son Historia Wambae. Envoyé par le souverain pour écraser la révolte d'Hilderic à Nîmes, Paul passa du côté des rebelles et fut élu roi par une assemblée réunie à Narbonne. Or, une fois reçu le serment de fidélité des révoltés ainsi que l'onction d'après sa lettre envoyée à Wamba ${ }^{25}$ - il se couronna lui-même d'une corona d'or autrefois offerte par le roi Récarède (586-601) à l'église Saint-Félix de Gérone $^{26}$. Cet auto-couronnement, loin de décrire une coutume orientale destinée à déconsidérer l'usurpation ${ }^{27}$, manifestait parfaitement la prise de pouvoir de Paul ; après sa défaite, ce dernier fut ensuite dépouillé de ses ornements royaux et, selon un rituel inverse d'humiliation, « couronné d'un laurier noir de cuir $»^{28}$.

11 Pourtant, dans l'Espagne wisigothique, ces couronnes votives manifestaient une royauté qui ne saurait se réduire à celle du donateur, puisqu'une couronne - certes plus modeste et dépourvue de lettres pendantes - fut offerte par un abbé Théodose (impossible à identifier) à saint Etienne ${ }^{29}$, peut-être à l'occasion de sa fête ${ }^{30}$; une autre, actuellement perdue mais dont il subsiste la croix pendante, le fut par un certain Sonnica à l'énigmatique église Santa María de Sorbaces ${ }^{31}$. Ces diverses donations expliquent les nombreuses couronnes recensées dans les trésors ecclésiastiques 
espagnols du haut Moyen Age : l'église Santa María de Nantón fut ainsi dotée en 871 par l'abbé Fulgaredus, le prêtre Pierre et la religieuse Berildi de divers biens meubles et immeubles, parmi lesquels figuraient des coronae $^{32}$. Si donc ces couronnes ne manifestaient pas exclusivement la royauté de leur donateur, elle symbolisaient alors nécessairement une autre royauté, celle du destinataire.

\section{L'autel couronné}

Dans l'iconographie, la corona était fréquemment associée à l'autel depuis l'époque paléochrétienne ${ }^{33}$. Les miniatures des Commentaires de l'Apocalypse de Beatus de Liébana en placent une souvent au-dessus ou à proximité immédiate d'un autel, qu'il s'agisse de celui surplombant les âmes des martyrs lors de l'ouverture du cinquième sceau (Ap VI, 9-11) ${ }^{34}$ ou de celui de l'église de Laodicée (par ex. Beatus de Gérone, 975) ${ }^{35}$. Cette étroite association iconographique de la couronne et de l'autel eut une concrétisation liturgique dans les sacramentaires hispaniques - et non dans ceux d'outre-Pyrénées. En effet, dans un ordo de bénédictions recopié en 1052 dans le Liber ordinum du monastère d'Albelda (Silos, Archivo monástico, 4$)^{36}$, le rituel de la vigile pascale reconnaissait à ces couronnes un rôle liturgique particulier : après la bénédiction d'une lampe et du cierge, la rubrique nous apprend que l'autel était à nouveau décoré et les couronnes suspendues durant la lecture du livre de la Genèse ${ }^{37}$. Celles-ci, habituellement présentes dans les églises wisigothiques, à tout le moins dans l'église cathédrale, étaient donc enlevées très certainement après la messe de la Cène du Jeudi Saint, lors de la cérémonie de dépouillement des autels, tandis que le chœur chantait l'antienne : « Mon âme est triste, triste à en mourir. Demeurez ici et veillez avec moi » (Mt 26, 38) ${ }^{38}$; l'enlèvement de ces couronnes participait de l'austérité ornementale, destinée à manifester la mort du Fils de Dieu, tandis que la liturgie du Vendredi Saint insistait sur la misère de l'homme et son espoir du pardon divin ${ }^{39}$.

Il faut donc comprendre au sens propre deux antiennes de la cérémonie de consécration d'une église, connue par l'Antiphonaire de la cathédrale de León (cod. 8, fol. 267r-v) - manuscrit approximativement daté du milieu du dixième siècle. En effet, après l'installation des reliques dans l'autel, ce dernier est consacré par l'évêque et décoré (Quando altare induunt et arcum), alors que l'on chante des extraits d'Isaïe et des Maccabées évoquant des couronnes parmi les ornements: Induit te Dominus tunica jucunditatis et inposuit tibi coronam et ornabit te ornamentis sanctis; puis Ornaberunt faciem templi coronis aureis et facta est laetitia magna in populo; statuerunt celebrare diem dedicationis altaris Domini, alleluia ${ }^{40}$.

Dans l'ordo du Liber ordinum de 1052 déjà évoqué, un texte de «bénédiction de couronne » confère une signification christique à cet objet :

Seigneur Jésus, toi qui es la couronne des saints, sanctifie par ta bénédiction cette couronne, afin que tu reçoives ces présents pour la parure de ta demeure, en ton honneur et pour l'ornement de l'autel, et que tu les acceptes des mains de ceux qui te les offrent par une pieuse générosité et une agréable considération ${ }^{41}$.

Or, à la différence de bon nombre d'autres bénédictions, ce rituel n'apparaît pas dans les sacramentaires d'outre-Pyrénées, ainsi que l'a justement remarqué Miquel Gros ${ }^{42}$. Cette étroite association entre la couronne, l'autel et le Christ, lui-même assimilé à la corona sanctorum, était donc typiquement hispanique. Elle reposait sur une théologie de la royauté christique et de l'autel, particulièrement vivante chez Isidore de Séville. En 
effet, l'autel était depuis longtemps l'objet d'une exégèse typologique, tropologique et anagogique ${ }^{43}$. Ainsi, dans son Interprétation exégétique des sens sacrés et spirituels ou Questions sur l'Ancien Testament ${ }^{44}$, Isidore reprit à Origène (traduit par Rufin) son assimilation symbolique et spirituelle de l'autel à l'Eglise, en tant que rassemblement des chrétiens; commentant le livre de Josué après la prise d'Aï (8, 30-31), l'évêque de Séville affirmait que les pierres utilisées par le prophète pour édifier son autel, figuraient les chrétiens, les "pierres vivantes" dont parle saint Pierre dans sa première lettre : «Vous êtes les pierres vivantes, édifiées en demeures spirituelles » (1 P 2, 5) ${ }^{45}$; intactes, non taillées, ces pierres représentaient ceux « sans impureté ni tache dans la chair et dans l'esprit, et qui n'ont pas accueilli les 'traits enflammés du malin' $($ Eph 6, 16) »; « ceux-ci constituent un seul autel dans l'unité de la foi et la concorde de la charité $\aleph^{46}$. Par ailleurs, dans son commentaire d'un passage de l'Exode, dans lequel Dieu interdit de bâtir un autel en pierre taillées (Ex 20, 25), Isidore reprit à saint Ambroise sa comparaison entre le corps du Christ et l'autel, qui en est son « image $»^{47}$.

Mais l'évêque de Séville établit une correspondance entre les deux allégories, christique et ecclésiale, la première justifiant la seconde. Ainsi, l'autel des holocaustes (Ex 27) « signifiait soit le corps du Christ, soit l'ensemble des saints; en eux brûle toujours le feu divin et la chair est sans cesse consommée ${ }^{48}$. De la sorte, « les pierres taillées sont ceux qui brisent l'unité et se séparent eux-mêmes de la société d'amour par la haine et le schisme: le Christ ne les accueille pas dans son corps; car la construction de son autel dissimulait la figure de son corps ». Ces pierres taillées sont évidemment à l'opposé des « pierres vivantes » de saint Pierre qui, « de fait, constituent un seul autel, puisqu'elles recherchent l'unité de la foi et la concorde de la charité $»^{49}$.

Si donc Isidore s'inspirait de nombreux auteurs anciens, comme il l'avouait lui-même dans sa préface ${ }^{50}$, il n'hésita pas, comme l'avait déjà remarqué Jacques Fontaine, à enrichir la doctrine antérieure au moyen de sa propre exégèse, allégorique ${ }^{51}$. Dans un recueil qui ne fut pas aussi «modeste » et « dépourvu d'originalité » que le pensait J. Chatillon $^{52}$, il proposa parfois une allégorie plus personnelle, selon un mouvement bien mis en valeur par Henri de Lubac : une allégorie allant du Christ à l'Eglise, puis de celleci à chaque fidèle ${ }^{53}$. Avec lui, l'autel devenait tout à la fois la figure du Christ, de l'Eglise et des saints.

Les couronnes placées au-dessus des autels manifestaient alors la royauté du Christ sur son Eglise - royauté dont la doctrine fut aussi particulièrement chère au sévillan. Dans la lignée d'Augustin, selon lequel «maintenant aussi l'Eglise est le royaume du Christ et le royaume des cieux $\|^{54}$, Isidore donna à cette royauté christique une véritable dimension ecclésiologique ${ }^{55}$. Comme Jésus signifiait sauveur et Christ roi, alors JésusChrist était le roi de l'Eglise, son épouse, comme naguère les rois de l'Ancien Testament gouvernaient le peuple juif ${ }^{56}$. Les chrétiens formaient un seul peuple de Dieu et royaume, dont le Christ était « l'unique prêtre et roi, car il s'offrit en hostie à Dieu le Père pour la rédemption de tous, et car, en tant que vrai roi, il gouverne son peuple dans le siècle présent et le jugera dans le futur $»^{57}$.

\section{Conclusion}

19 La suspension de couronnes votives au-dessus des autels connut une fortune particulière dans l'Espagne wisigothique catholique, ne serait-ce que par la richesse des pièces conservées et leur origine fréquemment royale. Alors que leur offrande était 
ritualisée (benedictio coronae), elles devinrent elles-mêmes des objets liturgiques, déposés depuis le soir du Jeudi Saint jusqu'à la vigile pascale.

Ces pratiques étaient indissociables de la réflexion antérieure des Pères, qui avaient déjà assimilé l'autel au Christ et à l'Eglise, avant qu'Isidore n'unisse pour la première fois ces deux allégories : chez le sévillan, l'autel était simultanément figure du Christ, de l'Eglise et des saints. La symbolique classique de la couronne - royauté du souverain, royauté du Christ et récompense de la vie éternelle (la corona sanctorum) ${ }^{58}$ - fut alors enrichie par la rencontre d'une pratique liturgique, d'une idéologie royale et d'une théologie: suspendre des couronnes traduisait la royauté du Christ sur son unique Eglise.

Cette pratique, vraisemblablement apparue avec le roi Reccarède, mettait tout particulièrement en valeur la rectitude doctrinale des rois, en contredisant directement l'hérésie d'Arius, qui niait au Christ toute divinité et toute véritable royauté. Elle témoignait aussi d'une précoce valorisation du lieu de l'autel, au moyen d'images reprises et approfondies après l'an mil dans un contexte théologique bien différent ${ }^{59}$ : dans l'église wisigothique, la signification de l'autel couronné est indissolublement christique et ecclésiale.

Mais, en offrant de telles couronnes, les rois ne faisaient pas seulement profession d'orthodoxie : leurs couronnes votives, qui l'emportaient sur toutes les autres par la taille et la richesse, ne pouvaient que rappeler la royauté de leur donateur. Royautés terrestre et céleste se trouvaient ainsi symboliquement unies, quand, à la même époque, Grégoire le Grand et Isidore de Séville définissaient dans leurs écrits la nature du pouvoir royal : tout à la fois délégation de Dieu et service rendu par un baptisé à ses frères dans le Christ-roi ${ }^{60}$.

Une première version de cet article a été publiée dans Eglises et pouvoirs (XIV Université d'été du "Carrefour d'histoire religieuse", Poitiers, 11-14 juillet 2005), Bruno Béthouart et Jérôme Grévy dir., Boulogne-sur-Mer, Maison de la Recherche en Sciences Humaines (Les Cahiers du Littoral - 2 -, 5), 2007, p. 71-83.

\section{NOTES}

1. L. Balmaseda, «Los avatares del tesoro de Guarrazar », dans El tesoro visigodo de Guarrazar, éd. A. Perea, Madrid, CSIC, 2001, p. 67-78.

2. L. Balmaseda, «El yacimiento y sus excavaciones », ibid., p. 79-117. Voir aussi : G. Ripoll, « Il tesoro di Guarrazar. La tradizione dell'oreficeria nella tarda antichità », dans Tesori. Forme e uso di accumulazione della ricchezza nell'alto medioevo (secoli V-XI), éd. S. Gelichi, C. La Rocca, Rome, Viella, 2004, p. 207-240.

3. Voir en dernier lieu le catalogue d'exposition: Torredonjimeno. Tresor, monarquia i litúrgia [Exposició, Barcelona, Córdoba, Madrid, Jaén, 2003-2005], Barcelone, 2003.

4. L.A. García Moreno, «El Tresor de Torredonjimeno. El seu context històric », dans ibid., p. 31-43, p. 42.

5. O. Grabar, «The Umayyad Dome of the Rock in Jerusalem », Ars Orientalis, 3, 1959, p. 33-62. 
6. J. Arce, «El conjunto votivo de Guarrazar : función y significado », dans El tesoro visigodo de Guarrazar, op. cit., p. 347-354, p. 352-354.

7. M.R. Valverde Castro, Ideología, simbolismo y ejercicio del poder real en la monarquía visigoda : un proceso de cambio, Salamanque, Universidad de Salamanca, 2000, p. 193-194.

8. F. Geyer (éd.), Itinera Hierosolymitana saeculi IIII-VIII, Corpus Scriptorum Ecclesiasticorum Latinorum, t. 39, Vienne, 1898, p. 171; cité par M. Gros I Pujol, « Aspectes litúrgics entorn de les corones votives visigòtiques », dans Torredonjimeno..., op. cit., p. 69-75, p. 71.

9. C.R. Brühl, «Kronen- und Krönungsbrauch im frühen und hohen Mittelalter », Historische Zeitschrift, 234, 1980, p. 155-163.

10. C. Morrisson, «Les insignes du pouvoir impérial au Ve et au VIe siècle ", dans Clovis : histoire et mémoire, dir. M. Rouche, t. I : Le baptême de Clovis, son écho à travers l'histoire, Paris, Presses de l'Université Paris-Sorbonne, 1997, p. 753-768.

11. Vie de saint Martin, 24, 4, éd. et trad. J. Fontaine, Paris, Cerf [Sources chrétiennes, 133], 1967, p. 306-309: Quodam enim die, praemissa prae se et circumjectus ipse luce purpurea, quo facilius claritate adsumpti fulgoris inluderet, veste etiam regia indutus, diademate ex gemmis auroque redimitus.

12. Contra: M.R. Valverde Castro, Ideología, simbolismo y ejercicio del poder real..., op. cit., p. 192-194 .

13. Liber Judicum, § I, 2, 6, éd. K. Zeumer, MGH : Leges sectio I (Leges nationum Germanicarum), t. I : Leges Visigothorum, Hannovre, 1902, p.33-456, p. 42 : Sicque bonus princeps, interna regens et externa conquirens (...) habiturus post labentia tempora requiem sempiterna, post luteum aurum celestem regnum, post diadema et purpuram gloriam et coronam.

14. I. Velázquez, «Las inscripciones del tesoro de Guarrazar », art. cit., p. 322-323.

15. Isidore de Séville, Etymologies, c. XIX-30, 1-3, éd. et trad. J. Oroz Reta, M.A. Marcos Casquero, Etimologías, t. II, Madrid, $1993^{2}$ [Biblioteca de Autores Cristianos, 434], p. 480 : Prima ornamenta corona insigne victoriae, sive regii honoris signum; quae ideo in capite regum ponitur, ad significandum circumfusos in orbe populos, quibus adcinctus quasi caput suum coronatur (...) Inperatores romani et reges quidam gentium aureas coronas utuntur.

16. Contra : P.D. King, Derecho y Sociedad en el reino visigodo, Madrid, Alianza, 1971, p. 12.

17. Contra : M. Reydellet, La royauté dans la littérature latine de Sidoine Appolinaire à Isidore de Séville, Rome-Paris, Ecole française de Rome-de Boccard, 1981 [Bibliothèque des Écoles françaises d'Athènes et de Rome, 243], p. 536-539.

18. Isidore de Séville, Historia Gothorum, c. LII, éd. C. Rodríguez Alonso, Las Historias de los Godos, Vandalos y Suevos de Isidoro de Sevilla : estudio, edicion critica y traducción, León, Centro de estudios e investigacion San Isidoro, 1975 [Fuentes y estudios de historia leonesa, 13], p. 260.

19. S. Gasparri, « Kingship Rituals and Ideology in Lombard Italy », Rituals of Power. From Late Antiquity to the Early Middle Ages, éd. F. Thews, J.L. Nelson, Leiden, Brill, 2000, p. 95-114, p. 109-110. 20. D'après I. Velázquez, ces couronnes de Guarrazar furent même offertes à l'église SaintPierre-et-Saint-Paul du prétoire à l'occasion d'un grand événement politique, religieux ou militaire; ainsi celle de Réceswinthe fut-elle peut-être donnée en 653 lors du huitième concile de Tolède (« Las inscripciones del tesoro de Guarrazar », art. cit., p. 322-329).

21. F. Mateu y Llopis, «Los atributos de la realeza en los tremises godos y las categorías diplomáticas coetáneas », Anales toledanos. Estudios sobre la España visigoda, 3, Tolède, 1971, p. 139-158, p. 150 ; A. Canto García, F. Martín Escudero, J. Vico Monteoliva, Monedas visigodas, Madrid, Real Academia de la Historia, 2002, $\mathrm{n}^{\circ} 2$ et 51.

22. P.D. King, Derecho y Sociedad en el reino visigodo, Madrid, Alianza, 1971, p. 12.

23. S. Silva Verastegui, «Los monasterios riojanos y el arte del miniatura en el alto Medioevo », dans III Semana de Estudios Medievales, Logroño, Instituto de Estudios riojanos, 1993, p. 213-231, p. 218-219.

24. S. Silva Verastegui, «La más antigua iconografía medieval de los reyes visigodos », dans Los Visigodos : historia y civilización, Universidad de Murcia, 1986, p. 537-558, p. 539, planches 6 et 7. 
25. Epistola Pauli, dans Patrologie Latine, t. 96, col. 761-762: In nomine Domini. Flavius Paulus unctus rex Orientalis, Wambae regi Austri.

26. Julien de Tolède, Historia Wambae regis, c. XXVI, éd. W. Levinson, Sancti Juliani Toletanae sedis episcopi Opera, t. I, Turnhout, Brepols [Corpus Christianorum, Series Latina 115], 1976, p. 522 : Unde factum est, ut vasa argenti quamplurima de thesauris dominicis rapta, et coronam illam auream, quam divae memoriae Reccaredus principis ad corpus beatissimi Felicis obtulerat, quam idem Paulus insano capiti suo imponere ausus est.

27. Contra : J. Arce, «El conjunto votivo de Guarrazar... », art. cit., p. 353 ; « Leovigildus rex y el ceremonial de la corte visigótica », dans Visigoti e Longobardi, dir. J. Arce, P. Delogu, Firenze, 2001, p. 79-92, p. 87-89.

28. Julien de Tolède, Historia Wambae regis, c. XXX, éd. cit., p. 772-774 : Rex ipse perditionis praeibat in capite, omni confusionis ignominia dignus et picea ex coreis laurea coronatus. A ce sujet, voir : M. De Jong, "Adding insult to injury : Julián de Toledo and his Historia Wambae », dans The Visigoths from the Migration Period to the Seventh Century. An Ethnographic Perspective, éd. P. Heather, Woodbridge, The Boydell Press, 1999, p. 373-402.

29. + OFFERET MUNUSCULUM S[AN]/C[T]O STEPHANO THEODOSIUS ABBA

30. I. Velázquez, « Las inscripciones del tesoro de Guarrazar », art. cit., p. 322-324, 326 et 330.

31. + IN D[E]I / NOM/INE / OFFERET / SONNICA / S[AN]C[T]E / MA/RIE / IN S/ORBA/CES. Voir : I. Velázquez, ibid., p. 332-335.

32. Ed. E. Sáez-C. Sáez, Colección diplomática del monasterio de Celanova (842-1230), t. I, Madrid, Universidad de Alcalá de Henares, 1996, n³, p. 62 : omnia jam dicta ipsas villas concedimus in ipso loco sanctorum, vela, cruces, signos, kalices, patenas, coronas, candelabros, libros sive et omnis tesaurus eclesie.

33. N. Mezoughi, «Le fragment de Beatus illustré conservé à Silos ( $1^{\mathrm{re}}$ partie) », Les Cahiers de Saint-Michel de Cuxa, 13, 1982, p. 125-151, p. 130-132.

34. N. Mezoughi, «Le fragment de Beatus... », art. cit., p. 130-133 et planches p. 146-151.

35. J.W. Williams, The illustrated Beatus: a corpus of the illustrations of the Commentary on the Apocalypse, London, Harvey Miller, t. II : The Ninth and Tenth Centuries, 1994, pl. 311 (fol. 100v).

36. R. Collins, "Continuity and Loss in Medieval Spanish Culture: the Evidence of MS Silos, Archivo Monástico 4 ", dans Medieval Spain. Culture, Conflict, and Coexistence. Studies in Honour of Angus MacKay, R. Collins, A. Goodman (éd.), New York, Palgrave Macmillan, 2002, p. 1-22.

37. Ordo die Sabbato in Vigilia Pasche, éd. J. Janini, Liber ordinum episcopal : Cod. Silos, Arch. Monástico, 4, Abadía de Silos, 1991 [Studia Silensia, 15], n 436, p. 190 (= M. Férotin, Le Liber Ordinum en usage dans l'Eglise wisigothique et mozarabe de l'Espagne du Ve au XIe siècle, Paris, 1904, col. 216) : Dum haec lectio legitur, expoliatur cereum benedictum illis foliis quibus circumdatus est et coronis. Et positis in patena, accedit episcopus et sedet in osteo cori. Accedentesque presbiteri cum diaconibus clerusque et omnis populus ad episcopum, accipiunt ab eo cerea benedicta. Sicque in hac lectione altare vestitur et corone desuper appenduntur.

38. Item de eodem die, éd. J. Janini, ibid., n 377, p. 175 (= M. Férotin, ibid., col. 192) : Et decantatur ab omnibus tribus vicibus, ita ut singulis quibusque vicibus cantatur, altare sanctum similiter singulis vestibus denudetur. Statimque tota luminaria ad radicem altaris fixa extinguuntur.

39. J. Pinell, « Il Venerdì Santo nelle antiche liturgie ispaniche », dans Dimensioni drammatiche della liturgia medioevale [Atti del I Convegno di Studio, Viterbe, 1976], Rome, Bulzoni, 1977, p. 127-138.

40. Antifonario visigótico-mozarabe de la catedral de León, L. Brou-J. Vives (éd.), t. I : Edición del texto, notas e indices, Madrid-Barcelone, CEISI [Monumenta Hispania Sacra, V, 1-2], 1959, p. 443.

41. Benedictio corone, éd. J. Janini, op. cit., $\mathrm{n}^{\circ}$ 305, p. 156 (= M. Férotin, op. cit., col. 165-166) : Jhesu Domine, qui es corona sanctorum, hanc coronam benedicendo sanctifica, ut pro decore domus tue et tui honore ac ornamento altaris accepta hec munera feras, et de manibus offerentium respectu hilari et pia benignitate accipias. 
42. M. Gros I Pujol, « Aspectes litúrgics... », art. cit., p. 72.

43. J. Braun, Der Christliche Altar, Munich, G. Koch, 1924, t. I, p. 750-755.

44. Présentation de l'œuvre et de sa tradition manuscrite par Jacques Elfassi: «Isidorus Hispalensis episcopus. Quaestiones in Vetus Testamentum ", dans La trasmissione dei testi latini del Medioevo/Mediaeval Latin Texts and their Transmission, dir. Paolo Chiesa, Lucia Castaldi, Firenze [Millennio Medievale 50, Stumenti e studi n.s. 8, Te.Tra I], Sismel-Ed. del Galluzo, 2004, p. 201-209. 45. Videamus itaque qui sunt isti lapides ex quibus aedificatur altare. Omnes igitur qui in Jesum Christum credunt, lapides vivi dicuntur, de quibus dicit Apostolus: "Vos estis lapides vivi, aedificati in domos spirituales " (Isidore, Quaestiones in Veterum Testamentum, In Josue, IX-1, dans Patrologie Latine, t. 83, col. 375) = Omnes qui in Christum Jesum credimus, lapides vivi esse dicimur, secundum quod Scriptura pronuntiat dicens: "Vos autem estis lapides vivi, aedificati domus spiritalis in sacerdotio sancto, ut offeratis spiritales hostias, acceptabiles Deo per Jesum Christum » (Origène, Homélies sur Josué, IX-1, éd. et trad. A. Jaubert, Paris, Cerf, 1960 [Sources chrétiennes, 71], p. 244).

46. His non est injectum ferrum, qui incorrupti et immaculati carne et spiritu sunt, et jacula maligni ignita non receperunt. Hi unum altare faciunt in unitate fidei concordiaque charitatis (Isidore, In Josue, 9, 2, éd. cit., col. 375) = Novit uniuscujusque conscientia, qui sit integer, qui sit incorruptus, impollutus, immaculatus in carne et in spiritu, qui sit ille cui ferrum non est injectum, id est qui «jacula maligni ignita » concupiscentiae non recepit, sed «scuto ea fidei » $($ Ac 1,14$)$ restinxit et reppulit. (...) Ego puto quod forte isiti tales lapides integri et incontaminati sancti apostoli esse possint, omnes simul unum altare facientes propter unanimitatem atque concordiam (Origène, Homélies sur Josué, c. IX-2, éd. cit., p. 246). 47. Ambroise, De Sacramentis, 1. IV, c. 2, et 1. V, c. 2, éd. et trad. B. Botte, Des Sacrements, Des Mystères, Paris, Cerf, 1961 [Sources Chrétiennes, 25bis], p. 122 : quid est enim altare Christi nisi forma corporis Christi? Cette assimilation apparaît déjà chez saint Cyrille d'Alexandrie : "l'autel c'est le Christ » (De adoratione, c. 9, dans Patrologie Grecque, t. 68, col. 647).

48. Ibid., c. XLVII (De altari), col. 312 : Altare autem illud corpus Christi significabat, sive omnes sanctos, in quibus ardet semper divinus ignis, et semper consumitur caro.

49. Quaestiones in Veterum Testamentum, In Exodum, c. XXXIII (De non sectis lapidibus faciendo), dans Patrologie Latine, t. 83, col. 304 : Deinde adjecit: «Quod si altare lapideum feceris mihi, non aedificabis illud de sectis lapidibus : si enim levaveris super id cultrum, polluetur». Secti lapides hi sunt qui unitatem scindunt, ac dividunt semetipsos a societate fraterna per odium vel schismata: tales in corpore suo non recipit Christus, cujus corporis figuram altaris illius constructio obumbrabat. Isti vero non secti lapides, ex quibus altare construi jubetur, hi sunt qui fidei morumque unitate solidantur, de quibus dicit Apostolus: "Vos estis lapides vivi, coaedificati in domus spirituales». His non est injectum ferrum, quia incorrupti sunt, et jacula maligni ignita non receperunt; quique unum altare faciunt, quia unitatem fidei vel concordiam charitatis sequuntur.

50. Ibid., Praefatio 5, col. 209: Sumpta itaque sunt ab auctoribus Origene, Victorino, Ambrosio, Hieronymo, Augustino, Fulgentio, Cassiano, ac nostri temporis insigniter eloquenti Gregorio. Sur le sujet, voir : U. Domínguez del Val, « La utilización de los padres por San Isidoro », dans Isidoriana, León, Centro de estudios e investigacion San Isidoro, 1961, p. 211-221.

51. J. Fontaine, «Grammaire sacrée et grammaire profane : Isidore de Séville devant l'exégèse biblique ", dans Los Visigodos : historia y civilización [Actas de la Semana Internacional de Estudios Visigóticos, Madrid - Toledo - Alcalá de Henares, 1985], Universidad de Murcia, 1986 [Antigüedad y cristianismo, 3], p. 311-329

52. J. Chatillon, « Isidore et Origène. Recherches sur les sources et l'influence des Quaestiones in Vetus Testamentum d'Isidore de Séville ", dans Mélanges Bibliques rédigés en l'honneur de André Robert, Paris, Bloud \& Gay, 1960, p. 537-547.

53. H. de Lubac, Les quatre sens de l'Ecriture, 4 vol.

54. Augustin, XX, 9, 1, éd. B. Dombart, A. Kalb, trad. G. Combès, La cité de Dieu, Livres XIX-XXII, Desclée, 1960 [Æuvres de saint Augustin, 37], p. 234-235 : Ergo et nunc ecclesia regnum Christi est regnumque caelorum. 
55. M. Reydellet, La royauté dans la littérature latine..., op. cit., p. 557 sqq.

56. Isidore de Séville, Etymologies, c. VII-2, 8, éd. cit., t. I [Biblioteca de Autores Cristianos, 433], p. 632 : Sicut enim Christus significat regem, ita Jesus significat salvatorem.

57. Quaestiones in Veterum Testamentum, In Genesin, XI, 8, dans Patrologie Latine, t. 83, col. 240 : Idem quoque unus sacerdos et rex, quia ad redemptionem omnium hostiam Deo Patri se ipsum obtulit, et ut verus rex in praesenti saeculo populum suum regit, et in futuro judicabit.

58. I. Velázquez, « Las inscripciones del tesoro de Guarrazar », art. cit., p. 325-326.

59. A. Rauwel, "Théologie de l'eucharistie et valorisation de l'autel à l'âge roman ", Hortus Artium Medievalium, 11, 2005, p. 177-181.

60. M. Reydellet, La royauté dans la littérature latine..., op. cit., p. 554-593.

\section{INDEX}

Mots-clés : autel, orfèvrerie, liturgie, royauté, Christ-roi, couronne votive Index géographique : Espagne wisigothique

\section{AUTEUR}

\section{THOMAS DESWARTE}

Maître de conférences en histoire médiévale, Université de Poitiers, Centre d'Etudes Supérieures de Civilisation Médiévale, Séminaire Interdisciplinaire de Recherche sur l'Espagne Médiévale thomas.deswarte@univ-poitiers.fr 